\title{
Dijkstra Algoritması Kullanılarak İpek Yolu Koridorları Arasında En Kısa Ulaştırma Güzergâhının Belirlenmesi
}

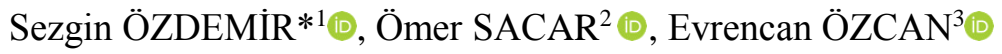 \\ ${ }^{1}$ TCDD Taşımacılık A.Ş. Genel Müdürlü̈̆̈̈, Ankara, Türkiye \\ ${ }^{2}$ Mehmet Emin Horoz Mesleki ve Teknik Anadolu Lisesi, İstanbul, Türkiye \\ ${ }^{3}$ Kırıkkale Üniversitesi, Endüstri Mühendisliği Bölümü, Kırıkkale, Türkiye \\ *ozdemir_sezgin@hotmail.com
}

(Alınış/Received: 16.10.2020, Kabul/Accepted: 19.12.2020, Yayımlama/Published: 31.01.2021)

Özet: Çin, çok taraflı ulaştırma politikaları ve 21. yy. İpek Yolunu oluşturma hedefi kapsamında 2013 yılında tarihi bir adım atmıştır. "Kuşak ve Yol” sloganı ile Pekin' den Londra' ya ulaşan yeni bir ticaret yolunun projesini açıklamış ve güzergâh ülkelerine iş birliği çağrısına bulunmuştur. Modern İpek Yolu olarak da adlandırılan bu proje; kara, deniz ve demiryolu taşımacılığının kullanılarak Çin ile güzergâhtaki 65 'den fazla ülkeyi birbirine bağlanmayı, bu ülkelerde dengeli ve sürdürülebilir ekonomik kalkınmaları hedeflemektedir. Türkiye coğrafi ve jeopolitik konumu sayesinde en önemli güzergâh ülkelerinden birisi olarak bu iş birliğinden en fazla beklentisi olan ülke durumundadır. Dolayısıyla Türkiye; demiryolu, karayolu, tüp geçitler ve boğaz köprüleri başta olmak üzere birçok önemli yatırıma imza atmıştır. Literatürde sosyal bilimler alanlarında İpek Yolu ile ilgili birçok çalışma mevcuttur. Fakat bu çalışmada konuya mühendislik uygulamaları yaklaşımıyla, tüm sosyal ve politik koşullardan bağımsız olarak optimal bir sonuç elde etme amacı güdülmüştür. Bu amaçla İpek yolu Koridorlarında Pekin'den Londra'ya ulaşan demiryolu ağ 1 için toplam 26 düğümden oluşan bir graf oluşturulmuş ve en kısa yolun hesaplanması için Dijkstra algoritması Python programlama dilinde kodlanarak çözülmüştür. Modern İpek Yolu veya Orta Koridor olarak adlandırılan güzergâhın Pekin-Londra arası en kısa demiryolu güzergâhı olduğu sonucuna ulaşılmıştır.

Anahtar kelimeler: Graf Teorisi, En Kısa Yol Problemi, Dijkstra Algoritması

\section{Determination of the Shortest Transport Route Among Silk Road Corridors by Using Dijkstra Algorithm}

\begin{abstract}
China took a historic step in 2013 within the scope of its multilateral transportation policies and the goal of creating the Silk Road of the 21st Century. With the slogan of "Belt and Road", it announced the project of a new trade route from Beijing to London and called for cooperation with the route countries. This project, also called the Modern Silk Road; It aims to connect China and more than 65 countries on the route by using land, sea and rail transport, and to achieve balanced and sustainable economic development in these countries. Turkey is one of the most important routes due to its geographical and geopolitical position moreover which has the greatest expectations from this cooperation. Therefore, Turkey has made many important investments, especially railway, highway, tube crossings and Bosphorus bridges. There are many studies in the literature about the Silk Road in social sciences. However, in this study, it is aimed to provide an optimal result by approaching the subject with the engineering applications independent from all social and political conditions. For this purpose, a graph consisting of a total of 26 nodes was created for the railway network reaching from Beijing-China to London-England in Silk Road Corridors and the shortest path has been calculated with Dijkstra's Algorithm scripted in Python. The results showed that the route which called the Modern Silk Road or Middle Corridor is the shortest railway route between Beijing and London.
\end{abstract}

Keywords: Graph Theory, Shortest Path Problem, Dijkstra's Algorithm 


\section{Giriş}

Taşımacılık, tarihin her aşamasında ülkeler için gerekli bir enstrüman olmuştur. Taşımacılık güzergâhları sadece ülke ihtiyacı için değil, bölgesel gelişmenin ve imparatorluk olmanın aracı olarak görülmüştür. Tarihte bu konuda öne çıkan en önemli yol ipek yoludur. İlk çağlardan itibaren insanlar ticaretin refah seviyesini yükselttiğini fark etmişlerdir. Ayrıca ticaret yapmakla beraber ticaret yollarına hâkim olmak, ya da ticaret yoluna yön vermek ülkelerin gelişme yolunda attığı adımlar olmuştur.

İpek yolu güzergâhları 20. yy’de bir önceki yüzyılların sonuçlarına göre kurgulanmış, dünya savaşlarından galip çıkan ülkelerin hâkimiyeti ve hegemonyasında ticaret devam etmiştir. 21 . yy. küreselleşmenin son evresini beraberinde getirmiş, haberleşme ve taşımacılık alanlarında yaşanan değişimler ülkeleri tekrar alternatif çözümlere itmektedir. Küreselleşme ile sürekli büyüyen ve dünya ticaretini eline alan Çin doğu-batı akslı ticaret politikaları gütmeye başlamıştır. Sadece ticari güç ile yetinmek istemeyen Çin, ticaret yollarına da hâkimiyet kurmak istemektedir. Uzun yıllardır istediği amaca yönelmek için yaptığı çalışmaları 2013 senesinde duyurduğu proje ile ülke politikası haline getirmiştir. Modern İpek Yolu olarak da bilinen, demir ipek yolu girişimi ile demir raylar üzerinde Çin-Avrupa hattında planlı ve programlı taşımacılık hedeflenmektedir. Temel amacı Asya-Avrupa hattındaki önemli ekonomiler arasında bir ulaştırma altyapısı, ticaret ve yatırım bağlantısı kurmak olan bu girişim, ilk kez 2013 yılında Çin Devlet Başkanı Xi Jinping tarafından duyurulmuştur. Çin'in başlattığı Kuşak ve Yol girişimi, küresel ekonomiye ivme kazandıracak dönüşümün tarihi bir adımı olarak nitelendirilmektedir. Türkiye de dâhil olmak üzere 65'ten fazla ülkenin ekonomik ve kültürel hayatına canlılık kazandırılmasını hedefleyen kuşak ve yol girişiminin, dünya nüfusunun üçte ikisini ve dünya gayri safi yurt içi hasılasının üçte birini kapsayacağı ön görülmektedir. Hızlı tren güzergâhları, hava limanları, petrol ve doğal gaz boru hatları gibi projelerin yer aldığı bu koridor tamamlandığında, hem Çin ile Türkiye arasındaki ticarette sevkiyat süresinin kısalması, hem de bu koridor üzerinde bulunan ülkeler arasındaki ticaretin artması beklenmektedir. [1]

İpek yolu güzergâh noktalarının Türkiye üzerinden geçmesi, hâlihazırda yapılan dev bütçeli lojistik yatırımların ivme kazanmasına yol açacaktır. Türkiye üzerinden demiryolunun geçtiği güzergâhlar canlandığı takdirde, endüstri, sanayi, tarım yatırımlarının gerçekleşmesi gibi olumlu etkileri görülecektir. Özellikle karayolunda yaşadığı uluslararası sıkıntıların demiryolu vasıtasıyla azalarak, taşımacılıkta tekdüze uygulamalar ile Türkiye'ye dayatılan bürokratik engellerin, sıkıntıların yaşanmamasını sağlayacaktır. İpek yolu güzergâhında farklı alternatif taşımaların ortaya çıkması, Türkiye'nin komşu ülkeleri ile yaşadığı taşımacılık engellemelerinin ortadan kalkmasını sağlayacağ kozunu ortadan kaldıracaktır. Bu durum mevcut hükümetlerin uluslararası siyasette elini güçlendirecektir [2].

Çin lideri Şi Jinping 2013 yılında 'Bir Kuşak, Bir Yol' adıyla Modern İpek Yolu projesini ilan etti. Tarihi İpek Yolu güzergâhında bulunan bütün ülkeleri bu projede yer almaya teşvik eden Çin, Asya, Afrika ve Avrupa'yı kapsayan büyük lojistik yatırımlar hedeflemektedir. Tarihi İpek Yolu'nun kuzey bölgesi geçmişten gelen yatırımlar ile en cazip bölge gibi görünse de Türkiye'den geçen Orta Koridor gerekli alt yapı yatırımları yapıldığında en ekonomik güzergâh olarak öne çıkmaktadır. Türkiye Bakü-Tiflis-Kars demiryolu hattını Gürcistan ve Azerbaycan ile ortaklaşa yaparak Hazar Bölgesinden demiryolunu Kars'a getirmiştir. Ayrıca Sivas'a kadar yapılan yüksek hızlı tren hatlarını Kars'a uzatmayı planlamaktadır. Marmaray ve 3. Köprü ile Avrupa'ya demiryolu geçişi sağlanarak kesintisiz demiryolu taşımacılığını Edirne'den Kars'a uzatmak Türkiye'nin taşımacılıktaki ana hedeflerinden olmuştur.

Türkiye'nin orta koridor üzerinde yatırımlar yapması, yüksek hızlı demiryolları kurarak alt yapısını güçlendirmesi, iç ve dış iki ana etmenle açıklanabilir: Birincisi doğu-batı aksında 
yüksek hızlı tren yolları ile Bakü-Tiflis-Kars hattının entegre edilmesi ile ülke içi lojistik alt yapı tamamlanacaktır. Bu yol ile bölgesel anlamda güneyde İran, kuzeyde Rusya'ya alternatif taşımacılık güzergâhı oluşacaktır. Bu ülkeler ile zaman zaman yaşan taşımacılık krizleri, BaküTiflis-Kars entegreli Hazar feribot geçişleri ile aşlacaktır. İkincisi ise zaman ve maliyet anlamında modern ipek yolunun en cazip taşıma koridorunu oluşturarak, taşımacılık yükü Türkiye'ye kayacaktır. Avrasya'nın iki yakasını bir araya getiren ipek yolu bölge enerji talebinin ve fiyatlarının sürekli arttığı bir dönemde zengin petrol ve doğalgaz yataklarıyla tarihteki öneminden daha fazlasını ifade etmektedir.

\section{Literatürde Yapılan Çalışmalar}

En kısa yol problemlerinin en yaygınlarından olan Dijkstra Algoritması literatürde ulaştırma, telekomünikasyon, enerji hatları, bilgisayar ağları, robot yolu planlamaları, acil durum kaçış güzergâhları başta olmak üzere birçok alanda karşımıza çıkmaktadır. Çalışmanın kapsamı olan ulaştırma alanında Dijkstra Algoritması yapılan çalışmalar bu kısımda bahsedilmiştir.

Kalkavi, Demir İpek Yolunda ülkemizdeki BTK (Bakü Tiflis Kars), Marmaray gibi projeleri dikkate alarak maliyet, süre, yük potansiyeli, güvenlik riski kriterlerini çok kriterli karar verme yöntemleri kullanarak incelemiş ve bu veriler altında Türkiye geçişi için en uygun güzergâhı belirlemiştir [3]. Çetin, lojistik merkez yer seçim değişkenleri açısından karşılaştırılmış, kriterlerin örneklemler ile değerlendirilmesi ile elde edilen veriler karşılaştırmalı analizlere tabi tutulmuş, çalışma kapsamında Türkiye'nin Çin-Almanya ulaştırma ağları ekseninde bir lojistik merkez olma potansiyeli incelenmiş ve bu potansiyelin deniz ticaretinin gelişimine etkileri tanımlayıcı araştırmalarla analiz etmiştir [4]. Şahin, insanlı ya da insansız gemilere yeni bir rota optimizasyon algoritması sunarak yakıt tüketimi, zaman ve emniyet faydası sağlanması amaçlayan 12 düğümlü bir çalışmada BAHS ile genişletilmiş Dijsktra algoritması uygulamıştır [5]. Karaş vd. afet esnasında meydana gelen çevresel ve insan kaynaklı etkenleri göz önüne alan ve gerçek zamanlı bir şekilde ağ analizini gerçekleştirerek kişiye özel tahliye güzergahını üreten, bir Akıllı Tahliye Modeli projesinde Dijkstra algoritmasından faydalanmışlardır [6]. Çakır vd. çalışmalarında katı atıkları toplama sistemine ait yol ağları, çalışma alanının demografik yapısı ve bölgede ortaya çıkan atık toplama ve taşıma operasyonlarında, CBS tabanlı rota ve güzergâh optimizasyonu ile 10 mahalleden oluşan şebekeye ait optimum güzergâh tespiti yapılmasında dijkstra algoritmasını kullanmışlardır [7]. Sungkwan vd. otomatik yönlendirmeli araçların enerji tüketiminin en aza indirilmesini ve optimum yolla çalışma süresinin iyileştirilmesi amacıyla yaptıkları çalışmada 12 düğümden oluşan şebekede dijkstra algoritmasını kullanmışlardır [8]. Wensi vd. Dijkstra algoritması ile mevcut optimum tahliye yolunu belirlemek için çalışacak bir model tasarlamışlardır [9]. Alyasin vd. akıllı mobil robotların hedefe ulaşmada en uygun yolu seçmeleri için Dijkstra algoritmasına dayanan şebeke ağı uygulaması yapmışlardır [10]. Zulfikar vd. Dijkstra ve Sweep algoritması kombinasyonları ile yaptıkları uygulama firmanın dağıtım şebekesini tekrar oluşturarak mevcut duruma göre mesafe ve seyahat süresinden \%9,3 oranında kazanım elde etmişlerdir [11]. Chang vd. Dijkstra Algoritmasını kullanarak kömür taşıma ağlarında en kısa yol probleminin araştırılmasını yapmışlardır [12]. Risald vd. Dijkstra ve Floyd-Warshall algoritmasının kombine edilmesi ile trafik kazalarındaki kazazedelerin en yakın hastaneye en kısa sürede ulaştırılabilmesi için güzergâh optimizasyonu geliştirmişlerdir [13]. Wang vd. bir konteyner gemisinin varış yerine en düşük maliyetle, daha kısa sürede ve varış süresi daha tahmin edilebilir bir şekilde ulaşması için dijkstra algoritmasını kullanmış ve gerçek yakıt verileri ile yapılan incelemede $\% 5$ tasarruf sağlandığı belirtilmiştir [14].

$\mathrm{Bu}$ çalışmada ele alınan uygulamanın literatürdeki diğer çalışmalardan farkı, demiryolu ulaştırma alanını kapsaması, ülkemiz ve dünya ulaştırma politikalarının merkezinde olan bir projeyi konu edinmesidir. Son yüzyılda küresel olarak artan demiryolu yatırımları ve birbirine alternatifler oluşturan demiryolu güzergâhları yeni bir problemi beraberinde getirmiştir. $\mathrm{Bu}$ 
problem, müşterilerin ihtiyaçlarını karşılayacak en uygun rotanın hangisi olduğu sorusudur. Çalışmada bu soruya çözüm bulunması amacıyla Pekin-Londra arasındaki demiryolu güzergâhları uzunlukları itibariyle ele alınmış ve problemin optimal çözümüne Dijiksta Algoritması ile ulaşılmıştır.

\section{Dijkstra algoritması}

Dijkstra Algoritması, bir graf üzerinde belirlenen başlangıç ve hedef düğümleri arasındaki en kısa güzergâhın bulunmasını sağlayan bir algoritmadır. Hollandalı bilgisayar bilimci Edsger Dijkstra tarafından 1959 yılında yayınlanan en kısa yol algoritmasıdır. Algoritma, ağırlıklı ve yönlü graflar için geliştirilmiştir. En kısa yolun belirlenmesinde, bir düğümden diğer bir düğüme geçerken olası en iyi yerel çözümü göz önüne alan Greedy yaklaşımı kullanılır ve iterasyonun her adımında bir sonraki düğüme ilerleme Greedy yaklaşımına göre yapılır [15].

En kısa yol problemlerinin çözümünde Dijkstra Algoritmasının yanı sıra Bellman-Ford, FloydWarshall ve Johnson Algoritmaları sıkılıkla kullanılanlar arasındadır. Dijkstra Algoritmanın avantajı diğer algoritmalara göre daha doğru ve kesin sonuçlar vermesi, döngülü veya döngüsüz tüm şebekelere uygulanabilmesi, dezavantajı ise yalnızca pozitif ağırlıklı ok bulunduran şebekelere uygulanabilmesidir.

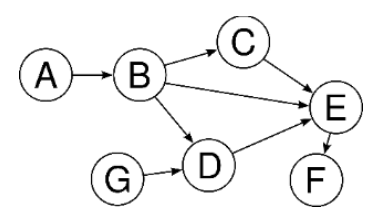

Şekil 1. Dijkstra algoritması şebeke örneği

Algoritmanın çalışma adımları:

1. İlk olarak Başlangıç düğümü seçilir ve "Sıfır" değeri atanır. Bu düğümden gidilebilen diğer tüm düğümlerin ağırlığı "geçici puan" olarak hesaplanır.

$$
S=\{s\}, \bar{S}=N-\{s\}, \quad L_{j}= \begin{cases}0 & j=s \text { ise } \\ L_{s j} & j \in \mathbb{T} \text { ise } \\ \infty & j \notin \mathbb{T} \text { ise }\end{cases}
$$

2. Başlangıç düğümünden direkt olarak gidilen dügü̈mlerden en az puana sahip olan dügümm işaretlenir, diğerleri ise aynı puanla devam eder. Direkt olarak ulaşılamayan diğer düğümlerin puanı "sonsuz değer" olarak varsayılır. En az puana sahip olan düğüm kalıcı olarak belirlenir.

$$
\begin{gathered}
\text { Ĕger } \mathbb{\Gamma}_{k} \in S \text { ise } L_{k}=\min _{j \in \bar{S}}\{L j\} \\
\text { Değilse } S=S \cup\{k\}, \quad \bar{S}=\bar{S}-\{k\}
\end{gathered}
$$

3. Kalıcı düğümden yola çıkarak henüz işaretlenmemiş diğer dügümlerin puanı hesaplanır. Daha az puanlı bir yol bulunduğunda dügüm puanı güncellenir. Başlangıç ve ulaşılması istenilen düğümler sabitlene kadar iterasyon devam eder, tüm düğümler sabitlendiğinde ise işlem biter.

$$
\begin{gathered}
j \in \mathbb{T}_{k} \cap \bar{S} \text { olmak üzere tüm } j \text { düğ̈ümleri için; } \\
L_{j}=\min \left\{L_{j} \cdot L_{k}+L_{k j}\right\}
\end{gathered}
$$

$N \quad$ : Şebekedeki tüm düğümlerin kümesi

$s \quad:$ Kalıcı etikete sahip olan dügümlerin kümesi 
$\bar{S} \quad$ : Geçici etikete sahip olan düğümlerin kümesi

$\mathbb{T}_{k} \quad: k$ düğümüne direkt bağlı olan düğümlerin kümesi

$L_{j} \quad: \quad j$ düğümünün başlangıç düğümüne olan uzaklığ1

$L_{k j} \quad$ : Komşu düğümler olan $k$ ve $j$ dügümleri arasındaki uzaklık

\section{Uygulama}

\subsection{Problemin tanımı ve verilerin elde edilmesi}

Günümüzde Asya ile Avrupa'yı, daha somut bir ifadeyle 28 ülkeyi birbirine bağlayan 114 bin kilometrelik Trans-Asya Demiryolu Ağı ile 141 bin kilometreyi bulan Asya Hızlı Demiryolu ağı projeleri yürütülmektedir. Uygulamada demiryolu koridorları kullanılarak Pekin'den Londra'ya demiryolu yük taşıması için en kısa koridor belirlenmiştir. Güzergâhların belirlenmesinde Mercator Çin Araştırmaları Enstitüsü' nün hazırlamış olduğu ve Şekil 2' de gösterilen haritadan faydalanılmıştır [16].

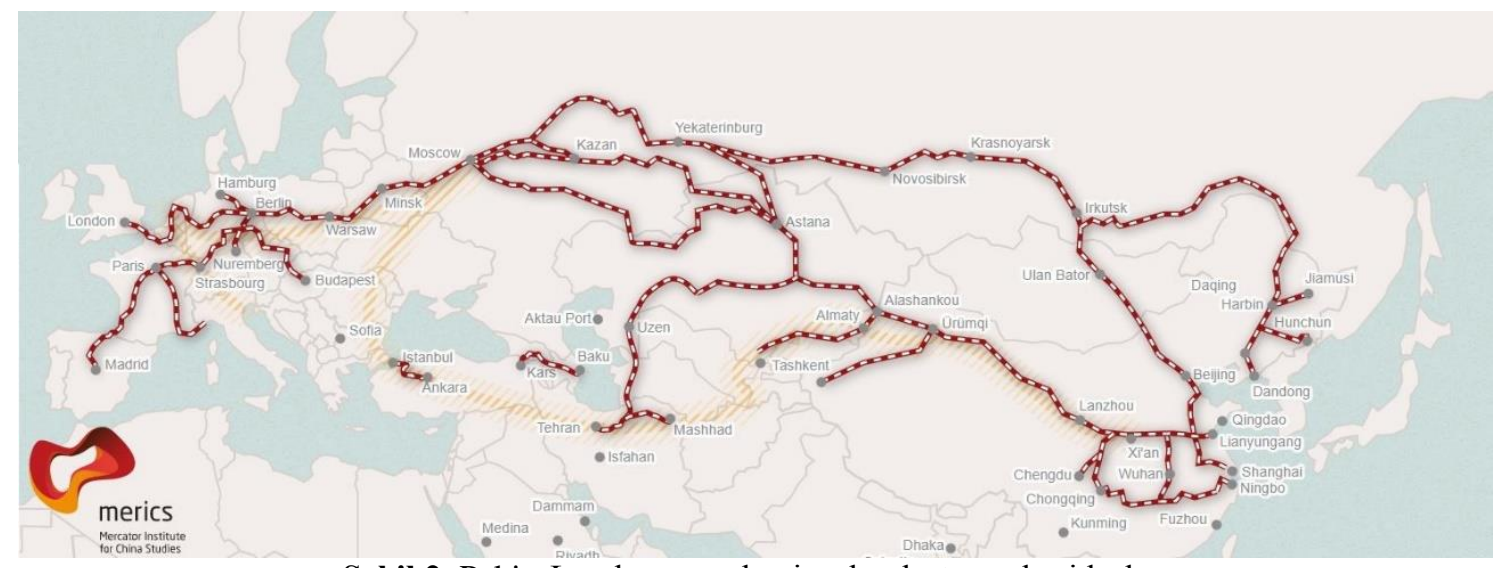

Şekil 2. Pekin-Londra arası demiryolu ulaştırma koridorları

Uygulamada ele alınan demiryolu haritasının kavşak noktaları ş̧ebekenin düğümlerini oluşturmaktadır. Geçiş ülkelerinin önemli demiryolu istasyonlarından oluşan şebeke toplam 26 düğümden oluşmaktadır. Düğümlerin graf üzerinde gösterilmesi ve kodlamada kullanım kolaylığı sağlanması amaciyla Tablo 1'de gösterildiği gibi alfabetik olarak numaralandırılmıştır.

Tablo 1. Şebekenin dügüüleri

\begin{tabular}{clcl}
\hline Düğüm Ad1 & İstasyon & Düğüm Ad1 & İstasyon \\
\hline A & Pekin & $\mathrm{N}$ & Bakü \\
$\mathrm{B}$ & Xi'an & $\mathrm{O}$ & Tahran \\
$\mathrm{C}$ & Lanzhou & $\mathrm{P}$ & Van \\
$\mathrm{D}$ & Irkutsk & $\mathrm{Q}$ & Kars \\
$\mathrm{E}$ & Urumqi & $\mathrm{R}$ & Ankara \\
$\mathrm{F}$ & Alashankou & $\mathrm{S}$ & Sofya \\
$\mathrm{G}$ & Altınkolat & $\mathrm{T}$ & Minsk \\
$\mathrm{H}$ & Astana & $\mathrm{U}$ & Budapeşte \\
$\mathrm{I}$ & Yekaterinburg & $\mathrm{V}$ & Warsaw \\
$\mathrm{J}$ & Kazan & $\mathrm{W}$ & Strasbourg \\
$\mathrm{K}$ & Moskova & $\mathrm{X}$ & Berlin \\
$\mathrm{L}$ & Taskent & $\mathrm{Y}$ & Lille \\
$\mathrm{M}$ & Aktau Limanı & $\mathrm{Z}$ & Londra \\
\hline
\end{tabular}

Dügümler arası ilişkiler Şekil 2'de verilen demiryolu haritası dikkate alınarak oluşturulmuştur. Her bir düğümü ifade eden geçiş ülkelerinin demiryolu istasyonları arasındaki mesafe ise 
kilometre birimi olarak hesaplanmıştır. Mesafe hesaplamasında kaynak olarak küresel seyahat planlama hizmeti sunan bir firmanın demiryolu mesafe hesaplama aracı kullanılmıştır [17].

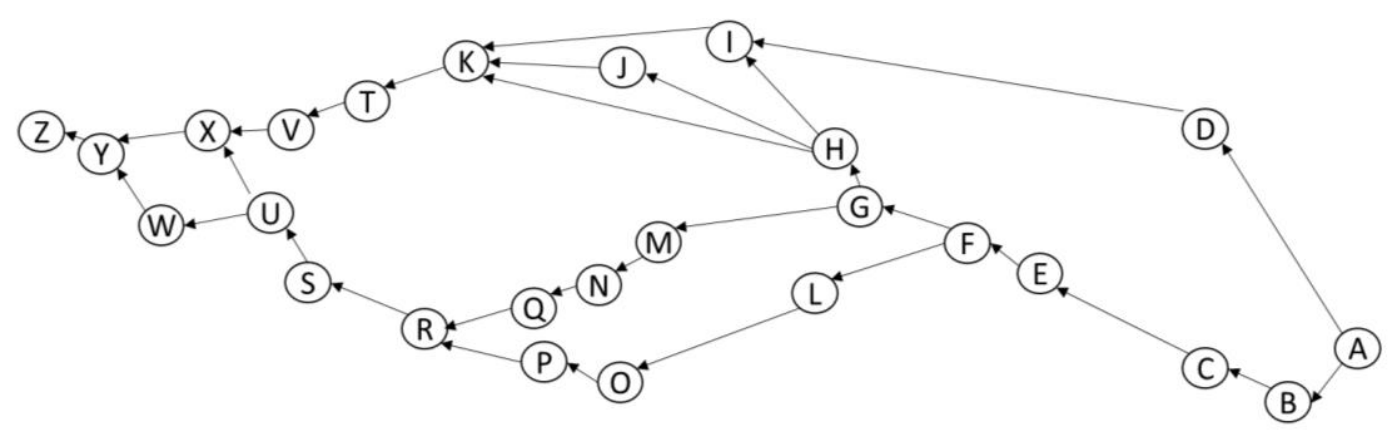

Şekil 3. Düğümler arasındaki ilişkiler

Temelini Şekil 2'deki demiryolu haritasının oluşturduğu şebeke düğümlerinin birbirleriyle olan bağlantıları graf üzerinde gösterilmiş ve Şekil 3'de verilmiştir.

Pekin'den Londra'ya uzanan en kısa güzergâhın hesaplanmasında ise en kısa yol algoritmalarından "Dijkstra Algoritması" kullanılmıştır. Algoritmanın yönlü ve ağırlıklı graflarda kullanılabilmesi, optimal sonuç vermesi, literatürde sıklıkla kullanılması nedenlerinden dolayı tercih edilmiştir

\subsection{Python kodlama dili problemin çözümü}

Python, ilk sürümü Guido Van Rossum tarafindan 1991'de ortaya konulmuş genel amaçlı bir programlama dilidir. Yorumlanan ve dinamik bir dil olan Python, esas olarak prosedürel ve nesne tabanlı programlama yaklaşımlarını ve belli bir oranda da fonksiyonel programlamayı desteklemektedir. Özgün, kolay kullanılabilir, etkileşimli, nesne yönelikli, popüler ve kütüphanesinin geniş olması Python kodlama dilini ön plana çıkarmıştır [18].

Dijkstra Algoritması problemin karakteristik özelliklerine ve gerçek verilere göre Python programlama dili 3.8.5 sürümünde kodlanmıştır. "PyCharm Community Edition 2020.2.2" paket programı aracılığıyla kodlar yazılmış olup kullanılan kaynak kodunun çözüm aşamaları Şekil 4'de verilmiştir.

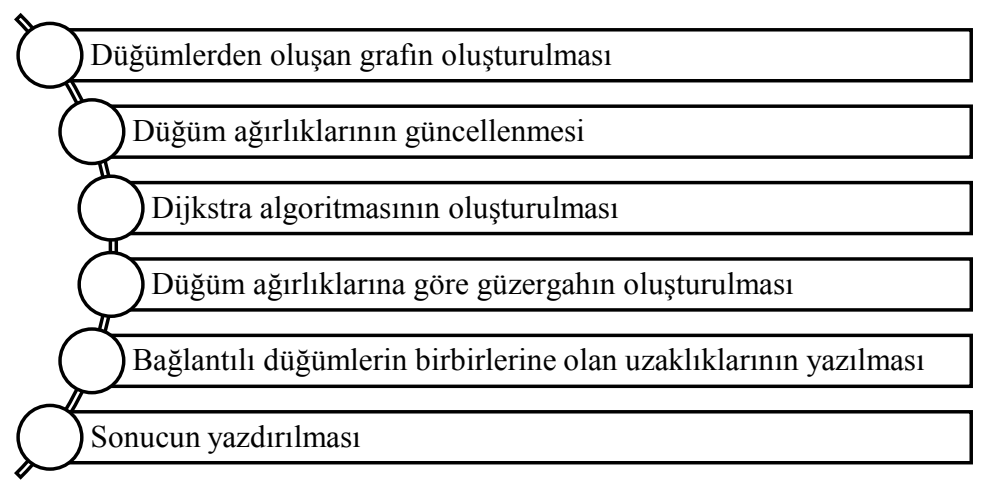

Şekil 4. Dijkstra algoritması için Python kodları yazım aşamaları 


\section{Bulgular}

Python programlama dili 3.8.5 sürümünde probleme özel uyarlanarak kodları yazılmış olan Dijkstra Algoritmasının çözümü ve yazdırma ekranına ait sonuç ekranı aşağıda verilmiştir.

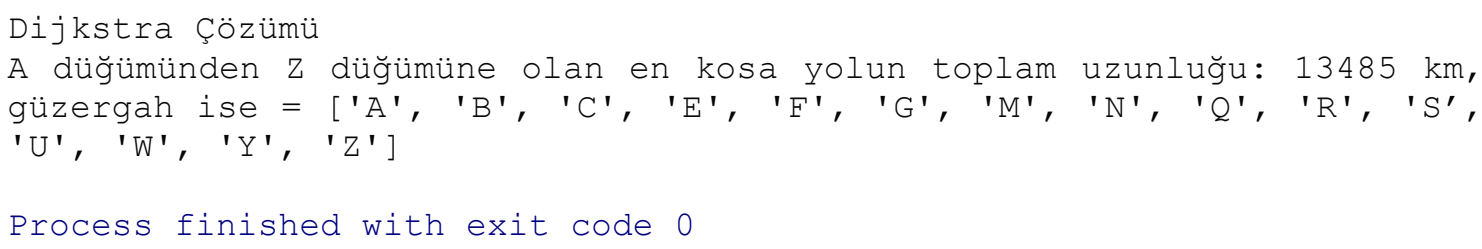

Tablo 1'de verilen şebekenin düğüm adlarına bakıldığında Pekin'den Londra'ya uzanan en kısa demiryolu güzergâhı şu şekilde ortaya çıkmıştır.

Dügüm adlarına göre; $[\mathrm{A} \rightarrow \mathrm{B} \rightarrow \mathrm{C} \rightarrow \mathrm{E} \rightarrow \mathrm{F} \rightarrow \mathrm{G} \rightarrow \mathrm{M} \rightarrow \mathrm{N} \rightarrow \mathrm{Q} \rightarrow \mathrm{R} \rightarrow \mathrm{S} \rightarrow \mathrm{U} \rightarrow \mathrm{W} \rightarrow \mathrm{Y} \rightarrow \mathrm{Z}]$

İstasyonlara göre ise; [Pekin $\rightarrow$ Xi'an $\rightarrow$ Lanzhou $\rightarrow$ Urumqi $\rightarrow$ Alashankou $\rightarrow$ Altınkolat $\rightarrow$ Aktau Liman $1 \rightarrow$ Bakü $\rightarrow$ Kars $\rightarrow$ Ankara $\rightarrow$ Sofya $\rightarrow$ Budapeşte $\rightarrow$ Strasbourg $\rightarrow$ Lille $\rightarrow$ Londra]

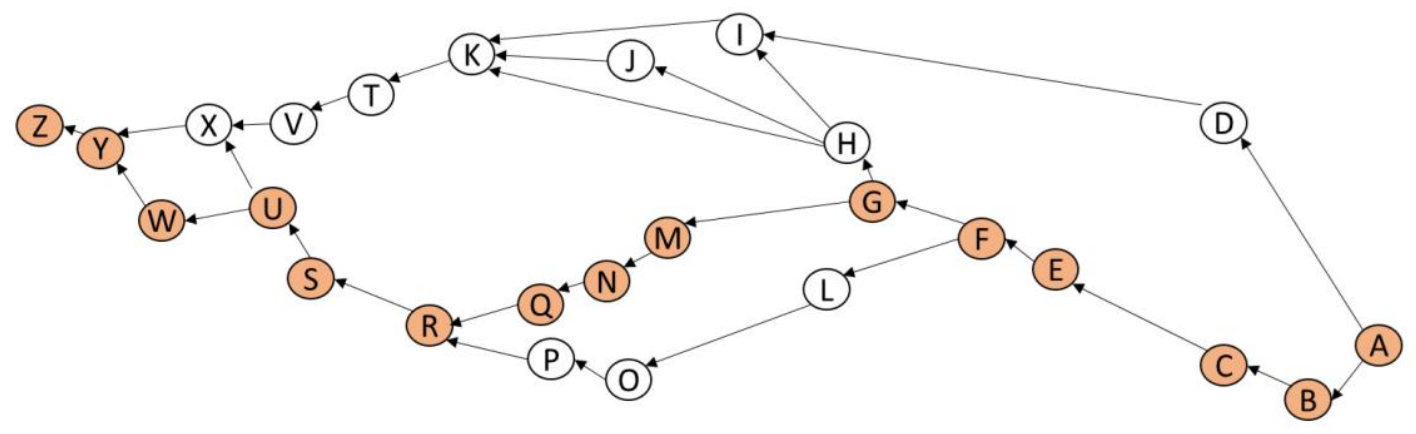

Şekil 5. Sonucun graf üzerinde gösterilmesi

Ortaya çıkan sonuç incelendiğinde, Pekin' den Londra' ya ulaşan en kısa yolun, ülkemizin de içerisinde yer aldığ 1 ve orta koridor olarak adlandırılan parkur olduğu sonucuna ulaşılmıştır. Sonucun oluşturduğu güzergâha ait koridorun graf üzerinde gösterilmesi Şekil 5'de verilmiş̧tir.

Sonuç güzergâhı üzerinde bulunan ve tarihçesi 1993 yılına dayanan Bakü-Tiflis-Kars demiryolu projesi, Türkiye üzerinden Marmaray geçişi ile Avrupa-Orta Asya arasında daha kısa ve daha güvenli bir yol üzerinden ulaşımın sağlanması hedefiyle 30 Ekim 2017 tarihinde fiili olarak açılmıştır. Marmaray tüp geçidinin de tamamen açılmasıyla proje ilk meyvesini vermeye başlamış ve Kasım 2019'da Çin'den Avrupa'ya bu güzergâh üzerinden ilk defa kesintisiz olarak bir tren işletilmiştir. Çin'in Xi'an kentinden Çek Cumhuriyeti Prag kentine ulaşan bu tren toplam $11.483 \mathrm{~km}$ mesafeyi 12 günde kat etmiştir [19]. Çalışmanın bulguları ve Çin'den Avrupa'ya yapılan bu ilk seferi karşılaştırdığımızda sonucun güvenirliliği ve gerçek hayat uygulamalarıyla örtüştüğü gözlenmiştir. 


\section{Sonuç}

Küresel demiryolu ağının her geçen gün gelişmesi, ülkeleri ve şirketleri demiryolu işletmeciliğinde etkin çözümlere ulaşma arayışı getirmiştir. Yüzyıllardır kullanılan ulaşım ağları tarihte olduğu gibi yeni güzergâhların keşfedilmesiyle, inşa edilmesiyle değişime uğramaktadır. Dünyanın en büyük ulaştırma güzergâhı sayılan İpek Yolu'nda da bu durum Modern İpek yolu ve Bir Kuşak Bir Yol isimleri ile projelendirilmiştir. Bu projenin mimarı olan Çin' in önceliğinde birçok ülke ulaştırma alanında milyarlarca dolar yatırım yapmaktadır. Demiryolları da bu yatırımların en büyük sahipleri arasındadır. Ülkemizin de Asya ve Avrupa geçişinde köprü konumunda olması, bu projenin en önemli ayağı konumunda olmasını sağlamıştır. Marmaray Projesi'nin tamamlanmasıyla Çin'den Londra'ya demiryoluyla kesintisiz yük taşınması mümkün hale gelmiş, böylece Çin ile Avrupa arasında toplam 30 gün olan taşıma süresi 12 güne kadar düşmüştür.

Uygulamada elde edilen sonuç son yıllardaki yatırımların karşılık bulduğunu ifade etmektedir. Özellikle 2019 yılından itibaren Çin-Avrupa arasında karşılıklı olarak yapılan demiryolu taşımalarının toplam seyir süreleri yatırımların fayda oranını yansıtmaktadır. Aynı zamanda bu uygulamadaki problemin çözüm sonuçları ile de örtüşmesi kullanılan algoritmanın optimalliğini bir kez daha doğrulamıştır. Açık kaynak kodu bulunması sayesinde benzer birçok ulaştırma probleminde uygulanabilir olması algoritmanın kullanılabilirliğini arttırmaktadır.

\section{Kaynakça}

[1] Hsbc Business, "Belt and Road," 2020. [Online]. Available: https://www.business.hsbc.com.tr/trtr/belt-and-road. [Accessed May, 01 2020].

[2] Ö. Sacar, "İpek yolu güzergahında yapılan lojistik etkinliklerin günümüz lojistik faaliyetleri ile karşılaştırılması," Balıkesir Üniversitesi Sosyal Bilimler Enstitüsü, Balıkesir, 2018.

[3] M.Y. Kankavi, "Demir ipekyolunda türkiye geçişi için en uygun güzergâh seçimi," Maltepe Üniversitesi, Sosyal Bilimler Enstitüsü, İstanbul, 2019.

[4] İ.B. Çetin, "Deniz ticaretinin geliştirilmesinde ulaştırma ağları için ilgi analizleri: Türkiye-AlmanyaÇin uygulamas1," DEÜ Sosyal Bilimleri Enstitüsü, İzmir, 2007.

[5] B. Şahin, "Route prioritization by using fuzzy analytic hierarchy process extended dijkstra algorithm," Journal of ETA Maritime Science, vol. 7, no. 1, pp. 3-15, 2018.

[6] İ.R. Karaş, Ü. Atila and M.K. Turan, "Kişiye özel akıllı tahliye modeli," Karabük Üniversitesi.

[7] M.E. Çakır, A.D. Yetiş, M.İ. Yeşilnacar and M.Ulukavak, "Katı atıklar için optimum güzergâh tespiti ve alansal dağılım haritalarının cbs ortamında oluşturulması:Suruç (Şanlıurfa) örneği," BEÜ Fen Bilimleri Dergisi BEU Journal of Science, vol. 8, no. 2, pp. 595-603, 2019.

[8] K. Sungkwan, J. Hojun, S. Minah and H. Dongsoo, "Optimal path planning of automated guided vehicle using dijkstra algorithm under dynamic conditions," 1th International Conference on Robot Intelligence Technology and Applications (RiTA) Robot Intelligence Technology and Applications Robot Intelligence Technology and Applications, Daejeon, Korea, 2019.

[9] W. Wang, G. Liu, X. Chen, Z. Liu, A.Zhang, Z. Xing, L. Liu and T.Fei, "Dijkstra Algorithm based building evacuation recognition computing and 1ot system design and implementation," 13th International Conference on Anti-counterfeiting, Security, and Identification (ASID) Anticounterfeiting, Security, and Identification, Xiamen, China, 2019.

[10] A. Alyasin, E.I. Abbas and S.D. Hasan, "An efficient optimal path finding for mobile robot based on dijkstra method," 4th Scientific International Conference Najaf (SICN) Naja, Al-Najef, Iraq, 2019.

[11] O.M. Zulfiqar, R.R. Isnanto and O.D. Nurhayati, "Optimal distribution route planning based on collaboration of dijkstra and sweep algorithm," 10th International Conference on Information Technology and Electrical Engineering (ICITEE) Information Technology and Electrical Engineering, Bali, Indonesia, 2018.

[12] H.Y. Chang, P.F. Wang, H.C. Chen, Y.Z. Chen and D.R. Chen, "On the study of shortest-path 
problem on coal-transportation networks using dijkstra's algorithm," International Conference on Consumer Electronics - Taiwan (ICCE-TW) Consumer Electronics, Taiwan, 2019.

[13] A.S. Risald, "Best routes selection using dijkstra and floyd-warshall algorithm," 11th International Conference on Information \& Communication Technology and System (ICTS), Surabaya, Indonesia, 2017.

[14] W. Wang, "A three-dimensional dijkstra's algorithm for multi-objective ship voyage optimization," Ocean Engineering, no. 186, pp. 1-13, 2019.

[15] E. W. Dijkstra, “A Note on Two Probles in Connexion with Graphs,” Numer. Math., 1959.

[16] Mercis, "Belt and Road", 2020. [Online]. Available: https://merics.org/en/analysis/mapping-beltand-road-initiative-where-we-stand. [Accessed May, 12 2020].

[17] Rome2Rio, "Railway Map", [Online]. Available:https://www.rome2rio.com/map/. [Accessed May, 13 2020].

[18] B.Malkoç, "Temel bilimler ve mühendislik eğitiminde programlama dili olarak python," Akademik Bilişim'12 - XIV. Akademik Bilişim Konferansı Bildirileri, Uşak, Turkey, Feb.2012

[19] Rayhaber, [Online]. Available:https://rayhaber.com/2019/11/cinden-yola-cikan-yuk-trenimarmarayi-kullanarak-avrupaya-gecti. [Accessed May, 12 2020].
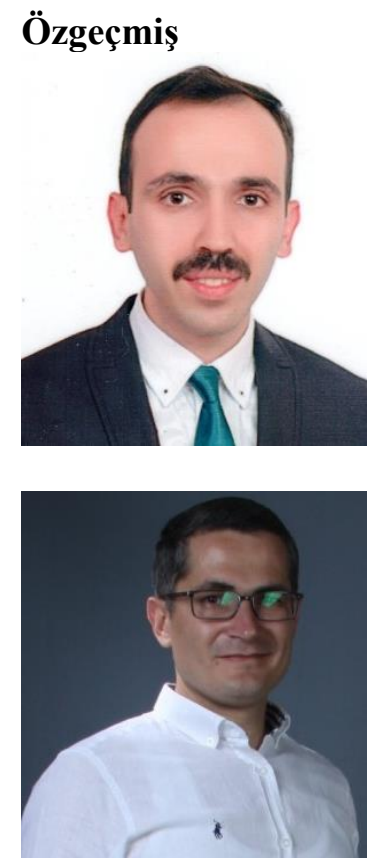

\section{Sezgin ÖZDEMIR}

1987 yılında Bartın'da doğdu. 2004 yılında Karabük Mustafa Yazıcı Lisesi'nden mezun oldu. 2010 y1lında İstanbul Üniversitesi Ulaştırma ve Lojistik, 2016 yılında Hoca Ahmet Yesevi Üniversitesi Endüstri Mühendisliği bölümlerinde lisans eğitimlerini tamamladı. Yüksek lisans eğitimine Kırıkkale Üniversitesi Endüstri Mühendisliği bölümünde devam etmektedir. 2012 yılından beri TCDD Taşımacılık A.Ş.' de çalışmaktadır.

E-Posta: ozdemir_sezgin@hotmail.com

\section{Ömer SACAR}

1986 yılında Bursa'da doğdu. 2003 senesinde Yıldırım Emirsultan Lisesi'nden mezun oldu. 2009'da İstanbul Üniversitesi Ulaştırma ve Lojistik Fakültesi'nde lisans eğitimini tamamladı. 2018'de Balıkesir Üniversitesi İşletme yüksek lisans eğitimini tamamladı. 2010 senesinden Türkiye'nin ilk lojistik öğretmenlerinden biri olarak MEB'de göreve başlayan SACAR, 2014'den itibaren Mehmet Emin Horoz MTAL'de göreve devam etmektedir. Lojistik alanında yüzlerce ögrenci ve eğitimciye yönelik Avrupa projeleri yazmakta ve yönetmektedir.

E-Posta: omersacar@hotmail.com

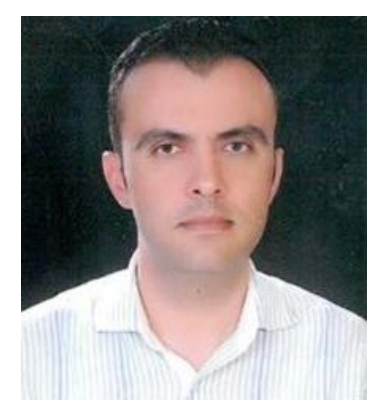

\section{Evrencan ÖZCAN}

Aslen Kırşehirli olan Özcan 1980 Ankara doğumludur. Lisans, Yüksek Lisans ve Doktora derecelerini sirasiyla 2003, 2007 ve 2013 yıllarında Gazi Üniversitesi Endüstri Mühendisliği Bölümünden almıştır. Özel sektörde 7 yıl devam eden mühendislik tecrübesinin ardından, 2010 y1lında Elektrik Üretim A.Ş.' ye atanan Özcan, Ocak 2018' den bu yana Kırıkkale Üniversitesi' nde Doç. Dr. Öğretim Üyesi unvanı ile meslek hayatına devam etmektedir.

E-Posta: evrencan.ozcan@kku.edu.tr

\section{Beyanlar:}

Bu makalede bilimsel araştırma ve yayın etiğine uyulmuştur.

Tüm yazarların eşit oranda katkısı olmuştur. 